\title{
The Effects of Allium sativum Extracts on Biofilm Formation and Activities of Six Pathogenic Bacteria
}

\author{
Zeinab Mohsenipour ${ }^{1}$; Mehdi Hassanshahian ${ }^{1, *}$ \\ ${ }^{1}$ Department of Biology, Faculty of Sciences, Shahid Bahonar University of Kerman, Kerman, IR Iran \\ ${ }^{*}$ Corresponding author: Mehdi Hassanshahian, Department of Biology, Faculty of Sciences, Shahid Bahonar University of Kerman, Kerman, IR Iran. Tel: +98-9132906971, Fax: \\ +98-3413202032, E-mail: mshahi@uk.ac.ir
}

Received: March 15, 2014; Revised: June 17, 2014; Accepted: July 21, 2014

\begin{abstract}
Background: Garlic is considered a rich source of many compounds, which shows antimicrobial effects. The ability of microorganisms to adhere to both biotic and abiotic surfaces and to form biofilm is responsible for a number of diseases of chronic nature, demonstrating extremely high resistance to antibiotics. Bacterial biofilms are complex communities of sessile microorganisms, embedded in an extracellular matrix and irreversibly attached to various surfaces.

Objectives: The present study evaluated the antimicrobial activity of Allium sativum extract against the biofilms of six pathogenic bacteria and their free-living forms. The clinical isolates in this study had not been studied in any other studies, especially in regard to biofilm disruption and inhibition of biofilm cell metabolic activity.

Materials and Methods: Antimicrobial activities of A. sativum L. extracts (methanol and ethanol extracts) against planktonic forms of bacteria were determined using the disc diffusion method. The minimum inhibitory concentration(MIC) and the minimum bactericidal concentration $(\mathrm{MBC})$ values were evaluated by a macrobroth dilution technique. The anti-biofilm effects were assessed by microtiter plate method.

Results: The results showed that the A. sativum L. extract discs did not have any zone of inhibition for the tested bacteria. However, The MIC values of A. sativum L. extracts $(0.078-2.5 \mathrm{mg} / \mathrm{mL})$ confirmed the high ability of these extracts for inhibition of planktonic bacteria. A. sativum L. extracts were efficient to inhibit biofilm structures and the concentration of each extract had a direct relation with the inhibitory effect. Conclusions: Finally, it can be suggested that the extracts of this plant be applied as antimicrobial agents against these pathogens, particularly in biofilm forms.
\end{abstract}

Keywords: Biofilms; Garlic; Pathogen; Enterobacteriaceae

\section{Background}

Since ancient times, crude herbal extracts of aromatic plants have been in use for different purposes such as food, drugs and perfumery (1). Plant-derived drugs remain an important resource, especially in developing countries, to combat serious diseases. Approximately, $60 \%-80 \%$ of the world's population still relies on traditional medicines for the treatment of common illnesses (2).

Phytoplants have been good alternatives to synthetic chemical antimicrobial agents and antibiotics, because of the serious side effects, antimicrobial resistance and the emergence of previously uncommon infections which have been increasing due to inappropriate or widespread overuse of antimicrobials. There are several reports in the scientific literature describing the antimicrobial properties of crude extracts prepared from plants (3).

Biofilm is an assemblage of surface-associated microbial cells which is enclosed in an extracellular polymeric substance matrix (4). Biofilm-embedded bacteria are more resistant to antimicrobial agents and the immune defense system than their planktonic counterparts (5). These biofilms accumulate in engineered systems such as heat exchangers, pipelines, processing equipment and storage tanks, and induce technical problems including reduction in heat transference, biocorrosion and associated environmental damages as well as product contaminations (6).

Furthermore, the presence of pathogenic bacterial communities is often associated with various chronic diseases (including cystic fibrosis, periodontitis, chronic prostatitis, otitis media, endocarditis and recurrent urinary tract infections) and is also responsible for the alarming spread of slime-associated nosocomial infections, mainly due to the increasing use of implanted medical devices of polymeric origin (7). Novel strategies are therefore required to deal with these biofilm-mediated problems (8). Therefore, to investigate the new compounds for defeating the microbial drug resistance especially in biofilm structures, this study was considered to evaluate the antibacterial potential of garlic methanol and ethanol extracts against six clinical bacterial isolates in planktonic and biofilm forms.

Garlic belongs to the Alliaceae family with the scientific

Copyright (C) 2015, Ahvaz Jundishapur University of Medical Sciences. This is an open-access article distributed under the terms of the Creative Commons Attribution-NonCommercial 4.0 International License (http://creativecommons.org/licenses/by-nc/4.0/) which permits copy and redistribute the material just in noncommercial usages, provided the original work is properly cited. 
name of Allium sativum. Garlic is widely used in culinary and medicine (9). Allium sativum L. has been an all-rounded treatment for preventing wound infection, common cold, malaria, cough and lung tuberculosis, hypertension, sexually transmitted diseases, mental illness, kidney diseases, liver diseases, asthma, and diabetes (10).

The therapeutic use of garlic has been recognized as a potential medicinal value to different microorganisms. For example, garlic extract has been an effective agent for controlling methicillin-resistant Escherichia coli, Salmonella typhi, Staphylococcus aureus and Bacillus cereus (11). In another study, the effects of water, ethanol and chloroform extracts of garlic against nosocomial S. aureus, E. coli, Streptococcus pneumoniae and Pseudomonas aeruginosa were investigated under various usage conditions, such as variations in temperatures and $\mathrm{pH}(12)$.

\section{Objectives}

The aim of this work was to study the antimicrobial activity of methanol and ethanol extracts of A. sativum L. against six pathogenic bacteria in planktonic and biofilm forms. These bacteria included S. aureus, B. cereus, S. pneumoniae, P. aeruginosa, E. coli and Klebsiella pneumoniae.

\section{Materials and Methods}

\subsection{Collection of Plant Material and Extraction}

Fresh garlic was purchased from the local market of Kerman, Iran. The garlic bulbs were peeled, rinsed with running water and cut into small pieces with a sterile knife and then air-dried under a shade for 14 days at room temperature. Thereafter, the dried garlic bulbs were reduced to coarse powder using pestle and grinded to fine powder using the Bosch electric blender (Bosch Limited, Germany).

Ten grams of the garlic powder was soaked in $100 \mathrm{~mL}$ of ethanol 80\% (Pars Chemic Co. Kerman, Iran) and methanol 96\% (Pars Chemic Co. Kerman, Iran) for 30 hours at $38^{\circ} \mathrm{C}$ with intermittent shaking. Then, the macerate was filtered using Whatman No. 1 filter paper and concentrated using a rotary evaporator and finally dried in oven in $40^{\circ} \mathrm{C}$ for 24 hours. One hundred milligrams of each dried extracts was dissolved in an appropriate volume of Dimethyl Sulfoxide (DMSO) 1\% and the volume was reached to $1 \mathrm{~mL}$ to get the final concentration at 100 $\mathrm{mg} / \mathrm{mL}$. Afterwards, the extracts were sterilized by passing through a $0.22 \mu \mathrm{m}$ filter membranes (Millipore ${ }^{\mathrm{TM}}$; MA, USA) and stored in a sterile dark bottle at $4^{\circ} \mathrm{C}$ for further use.

\subsection{Microbial Species and Culture Conditions}

The test microorganisms used in this study included six bacterial species, three Gram-positive (S. aureus, B. cereus and S. pneumoniae) and three Gram-negative (P. aeruginosa, E. coli and K. pneumoniae) ones. The tested microbial species were clinical isolates provided by the Faculty of Medicine, Department of Microbiology, Kerman University of Medical Sciences, Kerman, Iran.

The test microorganisms were maintained in NB/glycerol $(20 \%)$ at $80^{\circ} \mathrm{C}$. Nutrient agar (NA) (Merck, Germany) containing Luria-Bertani (LB) (Merck, Germany) was used to activate $S$. pneumoniae, while nutrient agar was used for other bacteria. Mueller Hinton agar (MHA) (Merck, Germany) medium was used for disc diffusion assay and nutrient broth (NB) (Merck, Germany) was used for minimum inhibitory concentration (MIC) and minimum bactericidal concentration (MBC) determinations. Mueller Hinton Agar was also used for the determination of MBC on these species (11). Tryptic soy broth (TSB) (Merck, Germany) was used for anti-biofilm assay. For S. pneumoniae in all the assessments, the medium was enriched by increasing LB.

\subsection{The Standard Antibiotic Used for Antimicrobial Assay}

Ciprofloxacin (Sigma, USA) ( $2 \mathrm{mg} / \mathrm{mL}$ ) was used as a reference antibiotic against bacterial species.

\subsection{Antibacterial Activity Testing Using Disc Diffu- sion Assay}

The disc diffusion method was selected for the determination of antimicrobial activity of alcoholic extracts of A. sativum. At first, an sterile $6 \mathrm{~mm}$ filter paper disc (Padtan Teb, Iran) was impregnated with the A. sativum L. methanol and ethanol extracts at the prepared concentration $(100 \mathrm{mg} / \mathrm{mL})$ and then it was left for about two hours and allowed to dry at $37^{\circ} \mathrm{C}$ for five hours (13). Discs containing ciprofloxacin $(2 \mathrm{mg} / \mathrm{mL})$, methanol $(96 \% \mathrm{v} / \mathrm{v})$, ethanol $(80 \% \mathrm{v} / \mathrm{v})$ and DMSO were used as controls. Subsequently, $500 \mu \mathrm{L}$ of the 18-hour culture of the test bacteria adjusted to $18 \mathrm{CFU} / \mathrm{mL}$ was spread on MHA plates using sterile swabs. Then, each of the discs was placed on the MHA plate inoculated with a lawn of the test microorganisms. The plates were incubated at $37^{\circ} \mathrm{C}$ for 18 hours. The antibacterial activities of A. sativum $\mathrm{L}$. extracts were evaluated by measuring the zones of inhibition.

\subsection{Minimum Inhibitory Concentration and Mini- mum Bacterial Concentration Assays}

MICs for planktonic cells were determined in NB by the broth macrodilution method, according to the approved standard of the clinical and laboratory standards institute (CLSI) (11). One milliliter of the overnight-grown NB cultures adjusted to $5 \times 10^{5} \mathrm{CFU} / \mathrm{mL}$ was added in a series of tubes containing $1 \mathrm{~mL}$ of various concentrations of each extract $(0.05-50 \mathrm{mg} / \mathrm{mL})$. After incubation for 18 hours at $37^{\circ} \mathrm{C}$, MIC was defined as the lowest concentration of the extracts that inhibited visible bacterial growth. Three control tubes, tubes contain- 
ing bacteria + negative control (NB), tubes containing bacteria $+\mathrm{NB}+$ ciprofloxacin $(2 \mathrm{mg} / \mathrm{mL}$ ) (positive control), tubes containing NB + extract concentration (extract control), and tubes containing NB (media control) were maintained for each test batch. For the assessed MBC values, $150 \mu \mathrm{L}$ of bacterial suspension from the MIC tubes was transferred into the MHA plates and then incubated at $37^{\circ} \mathrm{C}$ for 18 hours. After the incubation, the least concentration that inhibited bacterial growth on agar was recorded as $\mathrm{MBC}$.

\subsection{Inhibition of Biofilm Production}

Biofilm formation was determined according to O'Toole and Kolter with some modifications (14). Three appropriate concentrations $(12.5,25$ and $50 \mathrm{mg} / \mathrm{mL})$ of each extract were prepared from serial two-fold dilutions method in TSB medium. Of each concentration, $100 \mu \mathrm{L}$ was transferred into wells of a sterile 96-well polystyrene microtiter plate and then $100 \mu \mathrm{L}$ of the overnight grown TSB cultures, adjusted to an $\mathrm{OD}_{600 \mathrm{~nm}}$ equal to 0.2, was added to each well. All the microtiter plates were incubated for 24 hours at $37^{\circ} \mathrm{C}$. Four control wells, wells containing bacteria + TSB (negative control), wells containing bacteria + TSB + ciprofloxacin ( $2 \mathrm{mg} / \mathrm{mL}$ ) (positive control), wells containing TSB + extract concentration (extract control), and wells containing TSB (media control) were maintained for each test batch.

The adhered cell biomass was determined using crystal violet staining. At first, each well was emptied, washed three times with sterile Phosphate Buffered Saline (PBS) and fixed with $150 \mu \mathrm{L}$ methanol for 15 minutes. The bacterial cells that adhered to the wells were stained with $1 \%$ crystal violet solution (Gram staining set for microscopy, Merck, Germany) for 20 minutes. Thereafter, the colored biofilm was re-suspended in $160 \mu \mathrm{L}$ of glacial acetic acid $33 \%$ (15). The biomass was assessed using a microtiter plate reader (ELX-800, Biotech, India) at $630 \mathrm{~nm}$. The percent inhibition of biofilm formation was calculated using the ratio between the values of $\mathrm{OD}_{630 \mathrm{~nm}}$ wells with and without the extracts (Equation 1).

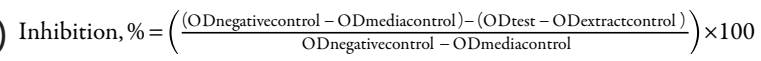

\subsection{Demolishing the Established Biofilm}

At first, to produce biofilms, $100 \mu \mathrm{L}$ of the overnight grown TSB cultures adjusted to an $\mathrm{OD}_{600 \mathrm{~nm}}$ equal to 0.2 was added to each well and the plates were incubated for 24 hours at $37^{\circ} \mathrm{C}$. Then, the nonadherent cells were gently removed by washing the biofilms three times with sterile PBS, and $100 \mu \mathrm{L}$ of three different garlic extract concentrations $(12.5,25$ and $50 \mathrm{mg} / \mathrm{mL}$ ) were pipetted into the wells. The microtiter plates were incubated for another 24 hours at $37^{\circ} \mathrm{C}$ and then the disruption of biofilm structures was determined by crystal violet staining (16). The control wells were the same as those described in section 3.6. The percentages of reduction in biofilm structures in the presence of different concentrations of the extracts were calculated employing the formula described earlier.

\subsection{Inhibition of Biofilm Metabolic Activity}

The effect of A. sativum L. upon the metabolic activity of preformed biofilm was measured as described by Ramage and Lopez-Ribot (17). Initially, the preformed biofilms were washed twice with sterile PBS and $100 \mu \mathrm{L}$ of each extract concentration $(12.5,25$ and $50 \mathrm{mg} / \mathrm{mL}$ ) was added into the wells. The plates were incubated for 24 hours at $37^{\circ} \mathrm{C}$ and then $50 \mu \mathrm{L}$ of a triphenyl tetrazolium chloride (TTC, Merck, Germany) solution was added, allowing the reaction to occur in the dark at $37^{\circ} \mathrm{C}$ for 3 hours. The final absorbance was read with a microplate reader at an excitation wavelength of $490 \mathrm{~nm}$. The control wells were the same as those described in section 3.6. The percentages of reduction of biofilm metabolic activity in the presence of different concentrations of the extracts were calculated employing the formula described earlier.

\subsection{Statistical Analysis}

The experimental data was analyzed using SPSS version 18.0 for windows. The differences between groups were examined for statistical significance using analysis of variance (ANOVA). Differences were considered significant if Pvalue was less than 0.01. All the experiments were conducted in triplicates.

\section{Results}

\subsection{Inhibitory Efficiency of Allium sativum L. Ex- tracts Against Planktonic Form of Pathogenic Bacteria}

The Zones of Inhibition (ZOI) for methanol and ethanol extracts of A. sativum L. are shown in Table 1 ; also, the MIC and MBC values of these extracts are illustrated in Table 2. In disc diffusion analysis, the extracts of $A$. sativum L. only had inhibitory effects on B. cereus (Figure 1). Although, these extracts did not have any inhibitory effect on other tested clinical bacterial pathogens. The results of A. sativum L. extracts effects on broth medium for the MIC test showed that these extracts had sufficient inhibitory effects on the tested bacteria. The MIC values of these extracts were the highest for $B$. cereus and the lowest for $S$. aureus between all the tested bacteria. According to these results, ethanol extract had a better inhibitory effect on planktonic form than the methanol extract. Although for inhibition of S. aureus the methanol extract was better than the ethanol extract, there was no difference between the inhibitory effects of ethanol and methanol extracts on S. pneumoniae. 
Mohsenipour Z et al.

\begin{tabular}{lcccc}
\hline Table 1. Antibacterial Activity of Allium sativum L. Alcoholic Extracts Against the Test Microorganisms Using Disc Diffusion Method ${ }^{\mathrm{a}, \mathrm{b}}$ \\
\hline Bacteria & Methanolic Extract & Ethanolic Extract & Ciprofloxacin & Solvent Control \\
\hline Staphylococcus aureus & - & - & $23 \pm 0.6$ & - \\
Bacillus cereus & $8.33 \pm 0.9$ & $7.67 \pm 0.5$ & $21 \pm 0.4$ & - \\
Streptococcus pneumoniae & - & - & $9.4 \pm 0.1$ & - \\
Pseudomonas aeruginosa & - & - & $24.6 \pm 0.3$ & - \\
Escherichia coli & - & - & $22.6 \pm 0.7$ & - \\
Klebsiella pneumoniae & - & - & $12 \pm 0.9$ & - \\
\hline $\begin{array}{l}\text { a Zone of inhibition is in mm. } \\
\text { b Values are presented as mean } \pm \text { SD. }\end{array}$ & & &
\end{tabular}

\begin{tabular}{lcccc}
\hline \multicolumn{1}{l}{$\begin{array}{l}\text { Table 2. Minimal Inhibitory Concentrations and Minimal Bactericidal Concentrations of Allium sativum L. on the Test Bacteria } \\
\text { Bacteria }\end{array}$} & \multicolumn{3}{c}{ MIC } \\
\cline { 2 - 5 } & Methanolic Extract & Ethanolic Extract & Methanolic Extract & Ethanolic Extract \\
\hline Staphylococcus aureus & 1.25 & 2.5 & 2.5 & 5 \\
Bacillus cereus & 0.156 & 0.078 & 0.625 & 2.5 \\
Streptococcus pneumoniae & 0.312 & 0.312 & 1.25 & 2.5 \\
Pseudomonas aeruginosa & 1.25 & 0.625 & 5 & 1.25 \\
Escherichia coli & 0.625 & 0.156 & 2.5 & 0.312 \\
Klebsiella pneumoniae & 0.312 & 0.156 & 0.625 & 0.625 \\
\hline
\end{tabular}

\footnotetext{
a Abbreviations: MIC, minimal Inhibitory Concentration; MBC, Minimal Bactericidal Concentration.

$\mathrm{b}$ The unit presented data is in $\mathrm{mg} / \mathrm{mL}$.
}

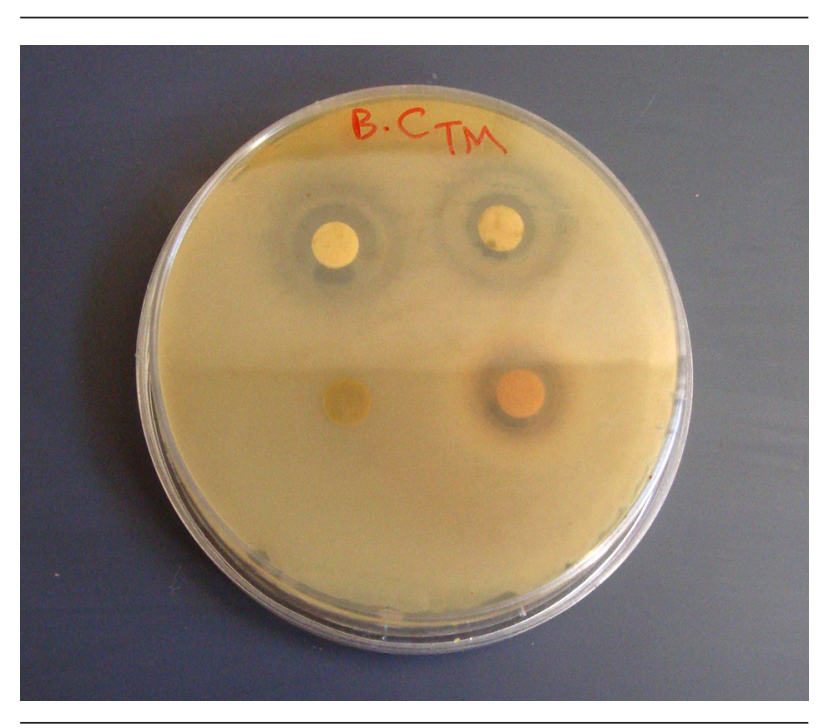

Figure 1. The Antibacterial Activity of Allium sativum L. Alcoholic Extracts Against Bacillus cereus Using Disc Diffusion Method

\subsection{The Inhibitory Effects of Allium sativum L. Ex- tracts Against Biofilm Structures}

The inhibitory efficiencies of each concentration of $\mathrm{A}$. sativum L. extracts on preventing biofilm formation, demolishing of biofilm structures and inhibition of metabolic activity of biofilm are shown in Figures 2, 3 and 4. Based on the examination performed for biofilm structures, it was
Figure 2. Reduction of Biofilm Formation for the Test Bacteria Treated With Different Concentrations of Allium sativum L. for 24 hours

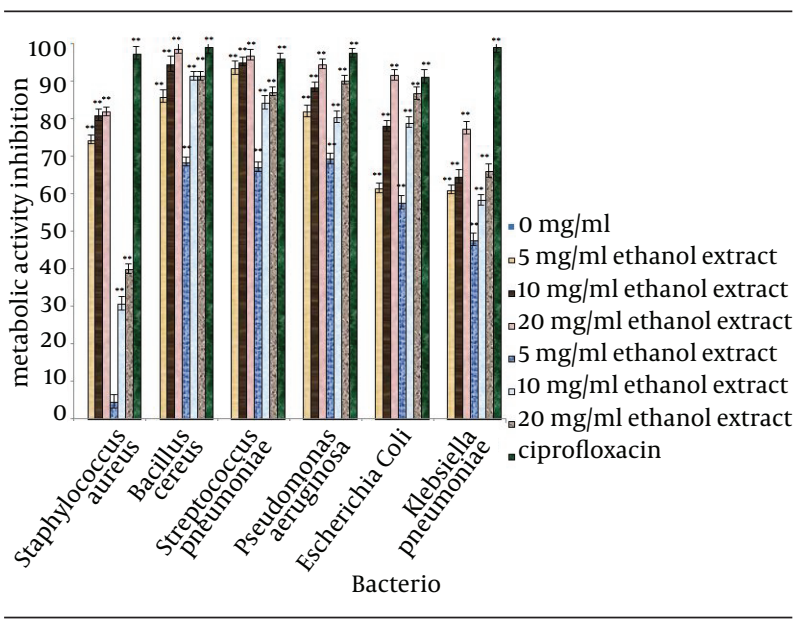

* The Differences between control (no inhibition) and treated with extracts $\left({ }^{*} \mathrm{P}<0.05,{ }^{* *} \mathrm{P}<0.001\right)$.

concluded that type of bacteria, type of solvent and concentration of extracts were significant at $1 \%$ level $(\mathrm{P}<0.01)$. According to the mean of the inhibitory effects of the selected concentrations of A. sativum L. extracts, these extracts had the ability to inhibit $50 \%$ of biofilm formation 
Figure 3. Disruption of Biofilm Formation for the Test Bacteria Treated With Different Concentrations of Allium sativum L. for 24 hours

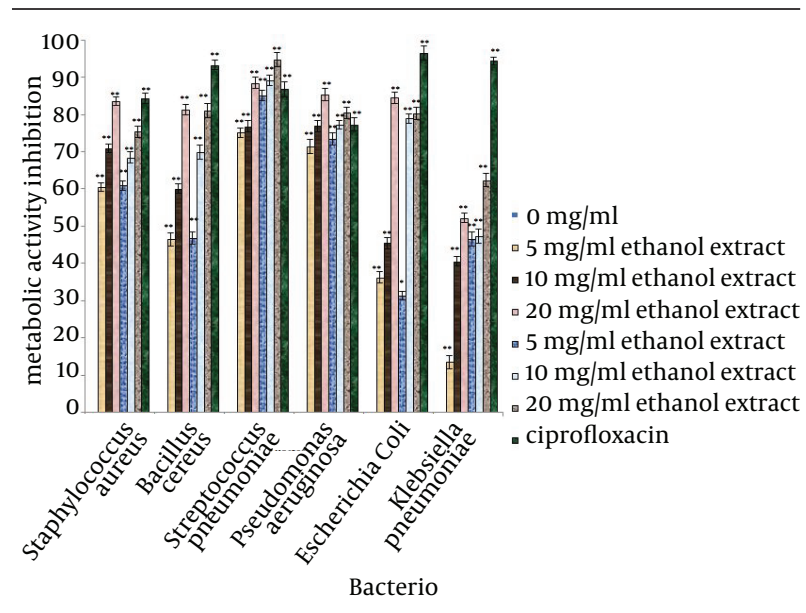

* Differences between control (no inhibition) and treated with extracts ( $\left.\mathrm{P}<0.05,{ }^{* *} \mathrm{P}<0.001\right)$.

Figure 4. Reduction of Biofilm Metabolic Activity for the Test Bacteria Treated with Different Concentrations of Allium sativum L. for 24 hours

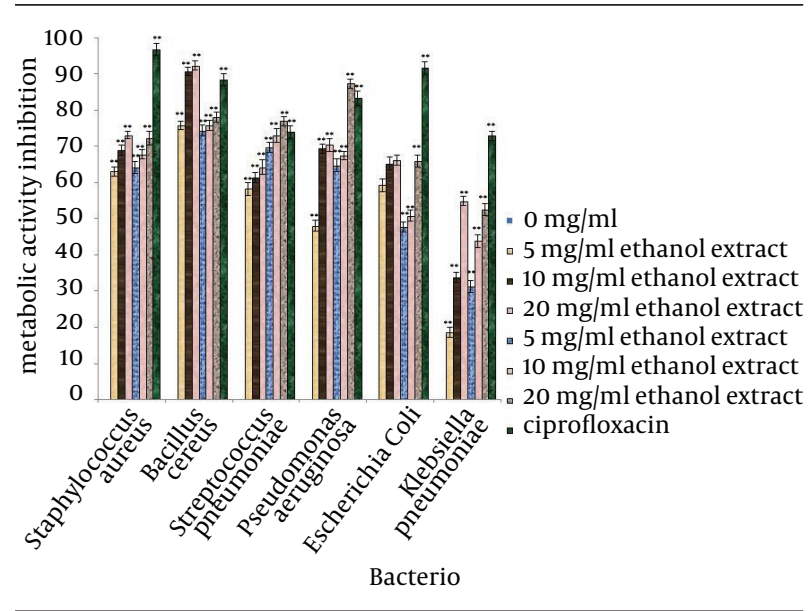

* Differences between control (no inhibition) and treated with extracts (* $\left.\mathrm{P}<0.05,{ }^{* *} \mathrm{P}<0.001\right)$.

in the tested bacteria. The highest inhibition of biofilm formation was observed against S. pneumoniae (88.51\%) and $B$. cereus (88.61\%) and the lowest inhibition was observed for biofilm formation of S. aureus (52.8\%). For destruction of biofilm structures, biofilms of S. pneumoniae were the most sensitive structures (84.89\%) and biofilm of K. pneumoniae had the lowest sensitivity. The metabolic activity of the bacteria in biofilms treated with A. sativum L. extracts had a remarkable decrease; the greatest reduction was observed in B. cereus biofilm (81.16\%) and the least reduction was observed in K. pneumoniae biofilm (39.17\%).

\section{Discussion}

Bacteria that grow as biofilm encased in a self-produced matrix are protected from host defenses and often ex- hibit reduced antibiotic susceptibility, contributing to the persistence of biofilm infections (8). For the last few years, many natural antimicrobial products have been isolated from a wide range of animals, plants and bacterial species. These compounds that comprise a diverse class of molecules used in natural host defense, may have therapeutic potentials in the treatment of infections in humans and are now considered to be alternative ways for future therapy (18).

The inhibitory effect of $A$. sativum L. extracts in the broth medium was higher than solid medium because in disk diffusion analysis, these extracts only inhibited the growth of B. cereus, but in the broth medium (for MIC test), they had sufficient inhibitory effects against all the tested clinical bacterial pathogens. According to these results, the antimicrobial compounds in A. sativum L. extracts, similar to other plant extracts, have low diffusion in solid media than broth media; thus, for favorable impact on solid media, much higher concentrations than broth media are needed. In addition, considering that the MIC values for these extracts were lower than the MBC values, these extracts have bacteriostatic properties. Some researchers have confirmed the antimicrobial properties of A. sativum L. against different microorganisms such as: B. subtilis, S. typhi, S. typhimurium, Proteus mirabilis and Chromobacterium violaceum. Similar to this study, other researchers also observed this inhibitory effect against bacteria on broth medium; thus, the results of the present study are in agreement with other studies (19-24).

Hovana et al. (24) showed that when the concentration of garlic aqueous, methanol and ethanol extracts increased in disks (125 - $500 \mathrm{mg} / \mathrm{mL}$ ), zones of inhibition were generated for $S$. aureus and E. coli. The inhibition zones of garlic extracts in this study were correlated with the high concentration of each disc. According to the low concentration of garlic extracts disk in our study, the zone of inhibition could not be observed. Some results confirmed that ethanol extracts of this plant had better inhibitory effects than methanol and aqueous extracts. However, the better efficiency of A. sativum L. ethanol extracts than methanol and aqueous extracts were confirmed in other studies (12). The present study confirmed that the inhibitory effect of garlic extract on planktonic forms was dependent to the types of bacterial isolates.

In deal with biofilm structures, A. sativum L. extracts were efficient. The inhibitory effects of the extracts were directly correlated with concentration. The ability of each extract for inhibition of biofilm formation was dependent to the type of solvent and the concentration of extract. The abilities of A. sativum L. alcoholic extracts in inhibition of biofilm formation of S. pneumoniae, P. aeruginosa and K. pneumoniae were more than that of destruction of biofilm of these bacteria. Although, the efficiencies of these extracts for destruction of biofilms of these bacteria were more than those of inhibition of metabolic activity. For E. coli biofilm, the abilities of A. sativum L. al- 
coholic extracts in inhibition of biofilm formation were more than those of the destruction of biofilm. Although, the efficiencies of these extracts for destruction of E. coli biofilm and inhibition of metabolic activity were the same. By treatment of B. cereus biofilm with A. sativum L. alcoholic extracts, it was confirmed that biofilm formation by this bacterium was better inhibited than the metabolic activity.

Since there are different mechanisms for biofilm formation and development by tested bacteria, various inhibitory mechanisms can be expected by A. sativum L. extracts. Considering the active components of A. sativum L. and the inhibitory mechanisms on biofilm structures which were not investigated in this research, it can be suggested by characterization of these compounds that it will be possible to interpret different inhibitory effects of these extracts among various tested clinical bacteria. The antibiofilm properties of A. sativum L. extracts have been more under attention in recent years. For example, Mathur et al. (25) showed that A. sativum L. essential oils can reduce biofilm formation of $K$. pneumoniae up to $47.5 \%$ on the surface of test tube and catheters. In the present study, garlic extracts could reduce $62.72 \%$ of biofilm formation of the bacteria. Therefore, this deference between the two study results may be correlated to different instruments selected for biofilm formation or differences between bacterial isolate in these studies.

Sandasi (16) confirmed the inhibitory effects of A. sativum L. extracts against planktonic forms and biofilm formation of Candida albicans, Listeria monocytogenes and $P$. aeruginosa. They showed that the inhibitory effects of alcoholic extracts were more than those of aqueous extracts. Our results are in agreement with the mentioned researches. In the present study, the biofilm formation of the clinical isolates of $P$. aeruginosa was inhibited up to $67.85 \%$ and this result is in agreement with Sandasi's study (16).The results obtained by Perez-Giraldo et al. (26) indicated that the MIC values of pure allicin obtained from $A$. sativum L. extracts remarkably inhibited the attachment of S. epidermidis into microplate wells. This study and our study confirmed the ability of garlic extracts to inhibit the attachment of Staphylococcus spices; therefore, they could inhibit the biofilm formation of these bacteria.According to the results of this research and other studies performed on extracts and essential oil of A. sativum L., the antimicrobial potential of this plant was confirmed and the extracts of this plant are suitable choices against pathogenic microorganisms.

\section{Acknowledgements}

The authors of this article are thankful from assistant research of Shahid Bahonar University of Kerman for financial support of this thesis.

\section{Authors' Contributions}

Zeinab Mohsenipour has performed the laboratory work of this research and Mehdi Hassanshahian has contributed in writing and statistical analysis of this study.

\section{Funding/Support}

All the equipment and materials were provided and supported by Shahid Bahonar University of Kerman, Kerman, IR Iran.

\section{References}

1. Cowan MM. Plant products as antimicrobial agents. Clin Microbiol Rev. 1999;12(4):564-82.

2. Taylor PW. Alternative natural sources for a new generation of antibacterial agents. Int J Antimicrob Agents. 2013;42(3):195-201.

3. Abdollahzadeh S, Mashouf R, Mortazavi H, Moghaddam M, Roozbahani N, Vahedi M. Antibacterial and antifungal activities of punica granatum peel extracts against oral pathogens. J Dent (Tehran). 2011;8(1):1-6.

4. Branda SS, Gonzalez-Pastor JE, Ben-Yehuda S, Losick R, Kolter R. Fruiting body formation by Bacillus subtilis. Proc Natl Acad Sci U S A. 2001;98(20):11621-6.

5. Schlag S, Nerz C, Birkenstock TA, Altenberend F, Gotz F. Inhibition of staphylococcal biofilm formation by nitrite. J Bacteriol. 2007;189(21):7911-9.

6. Geesey GG, Bryers JD. Biofouling of engineered materials and systems. In: Bryers JD editor. Biofilms II Process Analysis and Applications.. New York: Chichester; 2000. pp. 237-79.

7. Schito AM, Piatti G, Stauder M, Bisio A, Giacomelli E, Romussi $\mathrm{G}$, et al. Effects of demethylfruticuline A and fruticuline A from Salvia corrugata Vahl. on biofilm production in vitro by multiresistant strains of Staphylococcus aureus, Staphylococcus epidermidis and Enterococcus faecalis. Int J Antimicrob Agents. 2011;37(2):129-34.

8. Wang X, Yao X, Zhu Z, Tang T, Dai K, Sadovskaya I, et al. Effect of berberine on Staphylococcus epidermidis biofilm formation. Int JAntimicrob Agents. 2009;34(1):60-6.

9. Chand B. Antibacterial effect of garlic (allium sativum) and ginger (zingiber officinale) against staphylococcus aureus, salmonella typhi, escherichia coli and bacillus cereus. J of Microbiol, Biotech and Food Sci. 2013;2(4):2481-91.

10. Tessema B, Mulu A, Kassu A, Yismaw G. An in vitro assessment of the antibacterial effect of garlic (Allium sativum) on bacterial isolates from wound infections. Ethiop Med J. 2006;44(4):385-9.

11. Jeong SH, Song W, Bae IK, Kim HS, Kim JS, Park MJ, et al. Broth microdilution methods using B-lactamase inhibitors for the identification of Klebsiella pneumoniae carbapenemases and metallo-beta-lactamases in Gram-negative bacilli. Ann Clin Lab Sci. 2014;44(1):49-55.

12. EL-mahmood MA. Efficacy of crude extracts of garlic (Allium sativum Linn.) against nosocomial Escherichia coli, Staphylococcus aureus, Streptococcus pneumonieaand Pseudomonas aeruginosa. J Med Plants Res. 2009;3:179-85.

13. Andrews JM, Bsac Working Party On Susceptibility Testing ft BSAC standardized disc susceptibility testing method. J Antimicrob Chemother. 2001;48 Suppl 1:43-57.

14. O'Toole GA, Kolter R. Flagellar and twitching motility are necessary for Pseudomonas aeruginosa biofilm development. Mol Microbiol.1998;30(2):295-304.

15. Polaquini SR, Svidzinski TI, Kemmelmeier C, Gasparetto A. Effect of aqueous extract from Neem (Azadirachta indica A. Juss) on hydrophobicity, biofilm formation and adhesion in composite resin by Candida albicans. Arch Oral Biol. 2006;51(6):482-90.

16. Sandasi M. The effect of plant extraction on microbial biofilm formation and development. Department of Pharmaceutical Sciences, Faculty of Science. Tshwane: Tshwane University of Technology; 2008. Available from: http://search.ricest.ac.ir/Ricest/show12. aspx?Doc_ID=3384727.

17. Ramage G, Lopez-Ribot JL. Techniques for antifungal susceptibility testing of Candida albicans biofilms. Methods Mol Med. 2005;118:71-9. 


\section{Mohsenipour Z et al.}

18. Kuzma L, Rozalski M, Walencka E, Rozalska B, Wysokinska H Antimicrobial activity of diterpenoids from hairy roots of Salvia sclarea L.: salvipisone as a potential anti-biofilm agent active against antibiotic resistant Staphylococci. Phytomedicine. 2007;14(1):31-5.

19. Coppi A, Cabinian M, Mirelman D, Sinnis P. Antimalarial activity of allicin, a biologically active compound from garlic cloves. Antimicrob Agents Chemother. 2006;50(5):1731-7.

20. Gull I, Saeed M, Shaukat H, Aslam SM, Samra ZQ, Athar AM. Inhibitory effect of Allium sativum and Zingiber officinale extracts on clinically important drug resistant pathogenic bacteria. Ann Clin Microbiol Antimicrob. 2012;11:8.

21. Rahman S, Parvez AK, Islam R, Khan MH. Antibacterial activity of natural spices on multiple drug resistant Escherichia coli isolated from drinking water, Bangladesh. Ann Clin Microbiol Antimicrob. 2011;10:10.
22. Tsao SM, Hsu CC, Yin MC. Garlic extract and two diallyl sulphides inhibit methicillin-resistant Staphylococcus aureus infection in BALB/cA mice. J Antimicrob Chemother. 2003;52(6):974-80.

23. Richards RM, Xing DK. In vitro evaluation of the antimicrobial activities of selected lozenges. J Pharm Sci.1993;82(12):1218-20.

24. Hovana EIK, James US, James E, Egbobor EM, Egba AG, Eta ES, et al. Antibacterial and phytochemical studies of Allium sativum. New York Sci. J. 2011;4:123-8.

25. Mathur S, Gutte M, Paul D, Udgire M. Study the effect of essential oils on microbial biofilm formation by Klebsiella pneumonia. SchAcad J Biosci. 2013;1:76-9.

26. Perez-Giraldo C, Cruz-Villalon G, Sanchez-Silos R, MartinezRubio R, Blanco MT, Gomez-Garcia AC. In vitro activity of allicin against Staphylococcus epidermidis and influence of subinhibitory concentrations on biofilm formation. J Appl Microbiol. 2003;95(4):709-11. 